\title{
Talent Enrichment and Operational Sustainability in the Nigerian Telecommunication Sector
}

\author{
Christopher Akpotu, PhD \\ Department of Business Administration, \\ Niger-Delta University Wilberforce Island, \\ Amassoma, Nigeria. \\ Jasmine Tamunosiki-Amadi, PhD \\ Department of Business Administration, \\ Niger-Delta University Wilberforce Island, \\ Amassoma, Nigeria.
}

\begin{abstract}
Organisations are striving towards improved operational modes that enhance responsiveness to customer needs. One of the strategically considered means is talent enrichment practices for employees who are talent repository for firms. This study examined the empirical link between talent enrichment and operational sustainability. A sample of 216 employees the telecommunication sector in Nigeria was surveyed using questionnaire instrument. The data showed a positive and significant relationship between the constructs examined. This was noticeably strong with targeted skill mapping and operational effectiveness measured by quality service delivery, process improvement and timelines in service delivery. It is clear from the findings that talent enrichment remains a strategic imperative that engenders effective and efficient operations in work organisations. The findings hold strong theoretical implications in terms of operationalization of the variables that has been hitherto viewed as unidimensional. Its value-driven implication in terms of managerial policy is underscored.
\end{abstract}

Keywords: Talent, Enrichment, Mapping, Assessment, Competency, Targeted Learning

\section{INTRODUCTION}

Organisational operators are showing increased concern for operational effectiveness and sustainability. Increased technological advancement and breakthrough aimed at prompt response to customer demands are themselves sophisticated and therefore require a renewed set of work skills alongside sustaining relevant existing skills. Indeed, the change nature of work tasks that then characterized today's work place only imply that the inherent work skills of employees must be strategically enhanced to meet effective operational goals that prompt attainment of overall organisational goals. Importantly, this suggests critical attention at exploring, mining and targeting employee talents that are needed to undertake assigned task, creatively re-engineer work processes and timely deliver on goals. Gulate and Rueyingho (2008) have argued that as important and central as the discourse on talent enrichment may seem, there is seemingly organisational reticence that does not underscore its capability to trigger several other value-added actions aimed at goals. Often times according to Menalo and Akinson (2010), talent is viewed as a conventionally inherent and perhaps mundane resource that is readily accessible and is therefore given peripheral attention. A more articulated and synergized approach to promoting, harnessing and retaining employee talents is likely to provide a strategic means for effective and efficient service delivery. Managing talents for macro organisational outcome has earned scholarly concern within developed economies 
(Kandha and Sollywolf, 2000; Philas, 2004; Nebrand and Cullan, 2009; Parks and Lynda, 2010). These efforts underscore the fact that workplace desired outcomes requires organized actions that are goal-directed. The human resource possesses a repository of strategic talents and tacit knowledge reservoir for the organization. However there is dearth of empirical evidence on the talent enhancement practices and operational sustainability in work organisations. Some exciting works on talent management (Karien and Hilda, 2007; Basil, 2007; Jaya and Harrison, 2010; Molloway and Chanda, 2011) have examined it as a mono-construct which does not show the latent strength of the components on organisational outcomes. In the light of this, this paper examines the empirical relationship between talent enrichment and operational sustainability in the telecommunication sector.

Specifically, the study seek to investigate the relationship between competency assessment, targeted learning and talent mapping as dimensions of talent management and operational sustainability measures of quality service, process improvement and timely service delivery. The telecommunication industry has consistently witnessed technological breakthrough and increased need for quality service delivery by customers. Enhanced operational capabilities amongst firm in the sector are therefore required to gain competitive advantage. Achieving this also requires a talented workforce that has capacity to undertake tasks. This paper is structured with this part having the introduction, and followed with the literature review section. The next section has the methodology, the results and discussion. Finally, conclusion and policy implications closed the paper.

\section{LITERATURE REVIEW}

\section{Talent Enrichment}

The much consideration for critical human resource practices that build and sustain capacity of employees towards undertaking tasks has evolved into a huge literature (Everest, 2000; Pittson \& James, 2007; Koyen \& Neil, 2009; Onuegbu \& Adare, 2011; Ejemuta, 2011). Candy (2010) argued that with the challenging problems that are constant at work, they require new processes and systems which inturn require new work skills. One of the greatest challenges in workforce management according to Tamare (2006) is in acquiring and managing talents with a view to ensuring strategic leverage in competencies needed for sustainability. Much of the literature on talent management has shown that it is a strategic action aimed at enrichment of existing talent, and creating new ones that are value added. Simply, enrichment ensures both new acquisition and updating existing skills in addition to specific improvement of skills. Though enrichment of talent for effective and efficient work action is plausibly adduced, there is yet a theoretical indisposition to a systematic means of building talents. Notwithstanding, there is a guided taxonomical position taken by (Morton, 2005; Gandossy \& Bell, 2007; Jaya \& Harrison, 2010) which includes, assessment, targeting, mapping and renewal. Perini (2007) also presented a five-point model for enriching talents which includes attracting, selecting, engaging, developing and retaining. From the authors' perspective enrichment of talent stretches the scope of acquisition to use and necessarily enriching existing ones for competitive purposes. Ashhtor and Morton (2005) linked talent management with organisational scheme aimed at sustaining outstanding business results in a global economy, which means that talent enrichment is on its own a strategic ploy aimed at overall performance. Fistcher, Sugerim and Zadorskaya, (2001) have linked talent enrichment with labour force growth as it is capable of providing and entrenching new work skills for sustained retention at work. Enriching talents literature is extensively supportive of building employee potency and capacity to qualitatively undertake tasks that facilitate delivery on customer demands and achieving other stakeholder interests. Across sectors, the quantity of talent endowments that a firm has is a competitive arsenal that provides functional outcomes (Gandossy \& Bell, 2007; Benzil, 2009; Teks \& Sophill, 2010; Peterson, 2013). Ebeth (2009) 
espoused that firms with expanded talent portfolio are needed to withstand the imposing global dynamics to compete in the market place. It offers the leverage for new product development and allied innovative practices in addition to changing operational efficiency.

Aggrey and Gerald (2011) argues that talent enrichment is a process oriented organisational activity that entails identifying need areas alongside skills that are strategic to target goals. In doing this, competence analysis is considered important in order to make the identification. Burns \& James (2012) are of the view that assessing competencies is vital since talents are inner endowments that are seemingly intangible thereby creating identification difficulties. The authors noted the unavoidable place of competency assessment in talent enrichment which itself is tailored towards optimizing efficiency objective of firms. Through competency assessment an alignment is made between business strategy and business goals. Assessment of the characteristics of the talent of the workforce is needed for adoption of valued talent which Nabort, et al (2007) described as targeted learning. Targeted learning is a unique means of ensuring acquisition and storage of industry or function specific competencies (Leonard \& Zack, 2007; Teks \& Sophil, 2010). As a component of talent enrichment, it creates the path towards a coordinated approach for talent development overtime. Saaty (2008) noted that this is particularly useful for steady growth and efficiency within a segmented market.

Recently, different studies have given attention to the subject of intangible assets and their capacity to influence and improve business performance in which operational effectiveness has been operationalized as a measure of performance. Their empirical research findings have shown that, talents as intangible as they may appear, they create value for the organization. Particularly, acquiring and having the right talent mix relates with performance generally (Lee \& Yang, 2000; Marr \& Schuima, 2001; Perkman, 2002; Carlucci et al, 2004; Rumelt, 2008). The missing gap in the study is the generic measurement of the different constructs. This approach according to Robinson (2007) erodes the critical understanding of the benefits of the individual components especially in terms of talent enrichment that is process based and comes in parts. Benzil (2009) with reference to practical experiences at Cloverleaf Inc has discussed instruments and result to measure talent management impact on employee commitment. Other studies (Chong et al, 2000; Teece, 2000; McKay, 2008; Hanseen, et al, 2011) have their conceptual focus on quantitative measures of the relationship between talent management dynamics and performance using return on investment and profitability. Their findings indicated that the performance measures though are positively related; their utility value does not transcend financial measures, and are therefore not applicable to all functional aspects of work organization and strategic business objectives. Ekang \& Nelly (2010) noted that organisational objectives are multiple across functions, culminating to the overall goals. It simply means that it will amount to conceptual myopism if research effort does not reflect the entire latitude of objectives overtime and constitute basis for measurement. The analysis of the theoretical and empirical contribution in relation to the link between talent enrichment and operational effectiveness showed that the important factor that instigates talent enrichment is the organization strategy, which has been reported by Quincy (2011) that organization strategic context helps to identify targeted skills, assess and map out such talents for acquisition and enrichment. The implication is that any measurement that does not draw on the strategic context might be misleading especially when viewed against the targeted talent assessment and talent mapping that is tailored towards specialized talents that leverage firm effort at competitiveness. Talent enrichment at this point needs to be viewed as having a role to play in expected organisational goals. The task here is to establish the empirical link which has hitherto been generalized in term of performance. Operation is a standout function with its own end points and objectives. If the argument of contextualization is anything to go by, extant literature has shown a robust link between talent management construct and business 
performance which is a shift from contextual alignment of theory therefore, it is hypothesized in this study thus:

$\mathbf{H}_{\mathbf{o}}$ : Talent enrichment does not relate with operational sustainability.

\section{Conceptual Framework}

This study is a departure from the usual talent management discourse which has been examined as a mono-construct. Evidence shown so far in literature is consistent in treating talent management as an omnibus exercise that is theoretically deficient in its make-up. In this study, talent enrichment is specifically examined considering the uniqueness of the activities therein. Its theoretical components constitute the premise for investigating its relationship with operational sustainability which is also measured using quality service delivery, process improvement and timely service delivery. This is represented as figure 1 below;

Figure 1: Conceptual Model on Talent Enrichment and Operational Sustainability

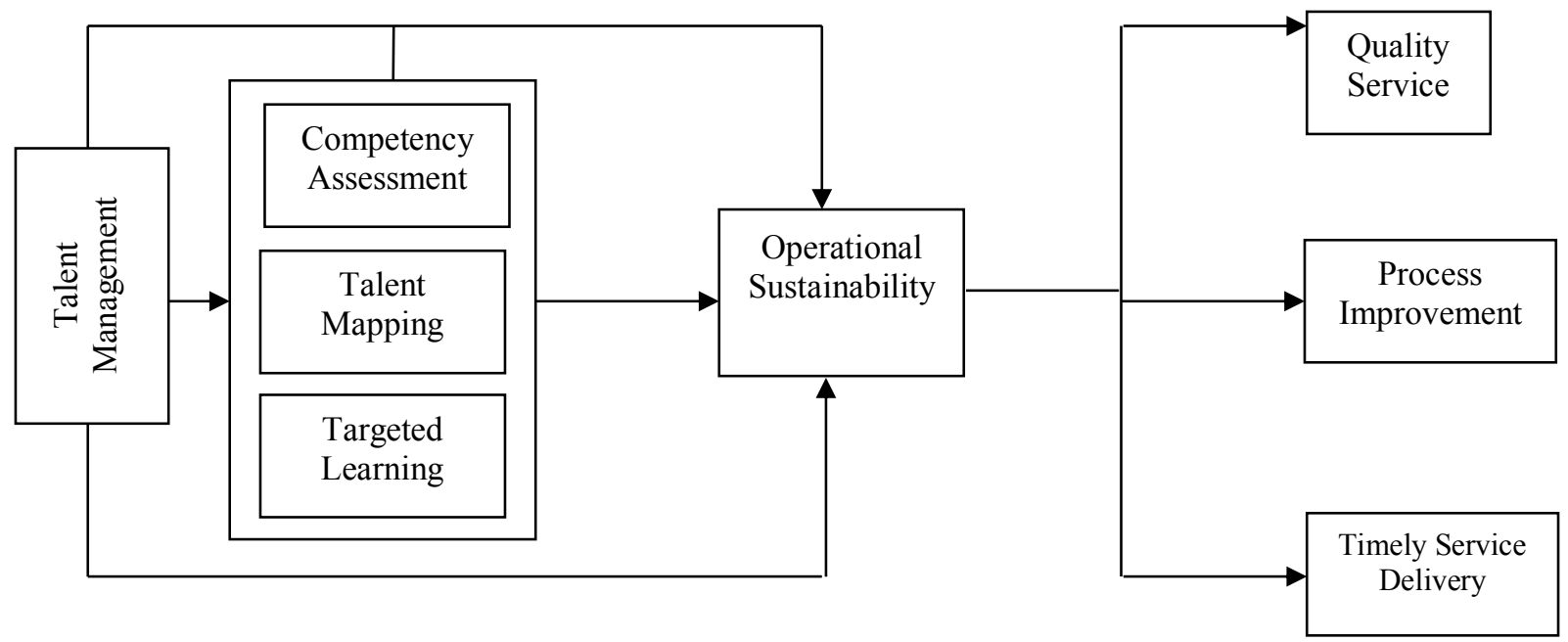

Source: Researcher's Desk Conceptualization (2019).

The conceptual framework shows the dimensions of talent management, which includes competency mapping, talent mapping and targeted learning. The link with the talent management dimensions with operational sustainability is illustrated. It further shows the measures of operational sustainability, which also includes quality service delivery, process improvement and timeliness in service delivery. The conceptual model indicates the likely relationship existing between talent management and operational sustainability in the studied organisations.

\section{METHODOLOGY/MEASUREMENT}

The study is conducted using a quantitative methodology which equally draws on positivist epistemology. This also means that deductive approach that requires stating apriori hypothesis was applicable. The design is strictly cross-sectional which allows generating data from a given sample at one instance. The survey instrument served as the means of generating data from a sample of human population (Ezeani, 1998). In this instance, the managers and operations officers of the telecommunication firms constitute the sample subjects. The sample subjects were judgmentally obtained based on the researchers fore knowledge of the characteristic of eligible participants for the study. In otherwords these sample subjects are vantage positioned to provide data on the subject investigated. The study primarily adapted the Quincy (2008) 23 items questionnaire on Talent Management which was also validated in Pittersbury (2010) with a reliability alpha of 0.73 . However, we choose to contextualize the instrument in the telecommunication sector since theirs was used in the educational sector. The peculiarity of 
the sector studied was noted. Again their scales were much domiciled in the talent management discourse and not enrichment.

In drawing up the questionnaire for the study, we had arranged the meetings with the human resource managers and operations officer in the regional offices. This is with a view to extracting commitment and confidence in providing critical questions that truly reflect the practices that best represent the examined constructs especially the predictor variable. This is also as a result of the need to contextualize the perspectives raised in relation to their organisational circumstances and uniqueness or work culture. During these meetings there were deliberate attempts to troubleshoot problems that talent-related that might be inherent within the workplace. It is with a view to designing an all embracing and indepth survey instrument.

The eventual survey instrument with 18 question items was prepared for the participants and mailed to them. They were given 2 weeks to respond and e-mail back through a centrally designed e-mail address, with a view to enhancing coordination and participation. We had earlier appealed through the Human Resource Management and Operation officers to participants to show commitment to responding to the survey question items as the final research findings will be made available to all participants and provide platform for strategic operational decisions.

\section{Ethical Consideration}

This research is under strict ethical consideration to ensure confidentiality of participants and participating firms in the telecommunication sector

\section{Model Specification}

Where

$$
Y=b_{0}+b_{1} X_{1}+b_{2} X_{2}+b_{3} X_{3}+\ldots \ldots \ldots \ldots b_{n} X_{n}+e
$$

$$
\begin{array}{ll}
\mathrm{b}_{0} & =\text { Intercept } \\
\mathrm{b}_{1}-\mathrm{b}_{3} & =\text { Slope/Co-efficient of } \mathrm{x} \\
\mathrm{Y} & =\text { Operational sustainability } \\
\mathrm{X}_{1} & =\text { Competence assessment } \\
\mathrm{X}_{2} & =\text { Targeted learning } \\
\mathrm{X}_{3} & =\text { Talent mapping }
\end{array}
$$

\section{RESULTS}

Descriptive Results and Correlational Matrix for Talent Enrichment and Operational Sustainability

\begin{tabular}{lcccccccc}
\hline & Mean & Std & \multicolumn{1}{c}{1} & 2 & 3 & 4 & 5 & 6 \\
\hline Competency Assessment & 3.31 & 1.931 & 1.00 & & & & & \\
Talent Mapping & 4.18 & 0.784 & $0.42^{* *}$ & 1.00 & & & & \\
Targeted Learning & 3.66 & 1.113 & $0.38^{* *}$ & $0.52^{* *}$ & 1.00 & & & \\
Quality & 3.92 & 1.432 & $0.61^{*}$ & $0.38^{*}$ & $0.57^{* *}$ & 1.00 & & \\
Process Improvement & 3.78 & .734 & $0.27^{*}$ & $0.31^{* *}$ & $0.67^{* *}$ & $0.47^{*}$ & 1.00 & \\
Timeliness & 4.41 & .652 & $0.53^{* *}$ & $0.44^{* *}$ & $0.22^{* *}$ & $0.53^{* *}$ & $0.39^{*}$ & 1.00 \\
\hline
\end{tabular}

**correlation significant @ 0.01

*correlation significant @ 0.05 


\section{Regression Coefficient for the Examined Variables}

\begin{tabular}{|c|c|c|c|c|c|c|}
\hline Model & $\mathbf{R}$ & $\mathbf{R}^{\mathbf{2}}$ & Adj Square & Std Error Estimate & F & Sig. \\
\hline 1 & .646 & 0.417 & .404 & .402 & 33.566 & $.000^{* *}$ \\
\hline
\end{tabular}

(a) Predictors (constant) competency assessment, talent mapping, targeted learning

The correlation results on the various dimensions of talent enrichment which includes competency assessment, talent mapping and targeted learning shows a positive and significant relationship with operational sustainability measures of quality service delivery in process improvement and timely service delivery. The multiple regression results further explains the degree of observed variability in the examined variables. From the results, $42.2 \%$ of the observed variability in operational sustainability is explained by talent enrichment.

Estimated Regression Coefficients on the Dimensions and Operational Sustainability

\begin{tabular}{|l|c|c|c|c|c|}
\hline \multirow{2}{*}{ Model } & \multicolumn{2}{|c|}{ Unstandardized Coefficients } & $\begin{array}{c}\text { Standardized } \\
\text { Coefficient }\end{array}$ & t & \multirow{2}{*}{ Sig } \\
\cline { 2 - 5 } & $\boldsymbol{\beta}$ & Std error & Beta & & \\
\hline Constant & 5.339 & 0.261 & & 24.341 & 0.000 \\
\hline Competency Assessment & 0.911 & 0.880 & 0.452 & -6.711 & 0.001 \\
\hline Talent Mapping & 0.764 & 0.513 & 0.051 & 2.168 & 0.018 \\
\hline Targeted Learning & 0.011 & 0.800 & 0.972 & 0.100 & 0.134 \\
\hline
\end{tabular}

Dependent Variable - Operational Sustainability

The table shows the impact of the various dimensions of the independent variable (talent enrichment) on the dependent variable (operational sustainability). From the result, targeted learning has the strongest impact of operational sustainability with a standardized beta $\beta$ of 0.972 followed by competency assessment with beta $\beta=0.452$ Talent mapping was the least with $\beta=0.051$

\section{DISCUSSION}

The objective of this study was to examine the empirical link between talent enrichment practices and operational sustainability. From the study results; it was found that talent enrichment component of competency assessment relates significantly with operational sustainability. It was also found that other components as operationalized which includes talent mapping and targeted learning positively and significantly relates with operational sustainability in the studied sector. The findings of the study give support to extant literature as shown in the works of Gandoky and Bell, (2007); Benzil, (2009); Teks \& Sophil, (2010). Their study findings though did not show the empirical position of the component parts having treated talent enrichment as mono construct; they emphasized a positive and significant relationship. Though Klarkson (2007) had examined empirical relationship between mapping and performance, operations which is a component was not one of the measures used. A distinct aspect of this study is its ability to show the impact of the explanatory dimensions of the independent variable. From the study findings, targeted learning show highest impact on operational sustainability. The outcome reinforced the findings of Quincy (2011) in which focused or targeted learning demonstrate potency in influencing firm capacity to undertake definite tasks and accomplishing same. All of these tends to show the shift in theoretical position which this study has found. The reason for the renewed outcome can be traced to the fact that talent enrichment unlike talent management is majorly targeted at buffering the inherent skills for operational efficiency which is a key strategic management objective in the studied firms. 


\section{CONCLUSION/POLICY IMPLICATIONS}

In this study which focused on talent enrichment and operational sustainability, attention is drawn at the strategic implication of employee talents as means of accomplishing work tasks and attaining desired goals. An essential component of this study is its typical capacity to bridge the knowledge gap as it relates with the talent construct which may be ordinarily viewed as inherent in the workplace therefore does not require enrichment even in the light of the heightened level of competition across sectors and geographical scope. Research questions based on the theoretical component of the construct were examined and it was found that talent enriched practices which include competency assessment, targeted learning and talent mapping are strategic actions that relates significantly with operational sustainability in the telecommunication sector. From the study results, competency assessment exposes skills need areas that are to be sourced, acquired or improvement of existing ones. In addition, targeted learning and mapping are enrichment exercises that have the main objective of ensuring that operational goals are met in the organization. The study concludes that talent enrichment duely practiced as operationalized in the study ensures operational sustainability. The findings presents a thrust for organized managerial actions that undoubtedly ensures sustained operational efforts that ultimately facilitates goal attainment in work organisations. It is common knowledge that the hi-tech nature of the telecommunication industry with rapid product innovation practices a talented workforce with unique competences is also needed. The need for continuous skill update is imperative for capacity building and operational readiness that facilitates effective customer service delivery. Insatiable managerial quest for providing skill reservoir and renewal is essential for effective conduct of operations.

\section{SUGGESTED FOR FURTHER STUDIES}

Future research in the area of talent management generally is imperative especially when viewed against the backdrop of emerging technologies and development goals of developing economies of the world. The dimension of the construct as used in this study can also be researched in the fast growing financial sector with new work processes. This can also be the case with the hospitality sector with revolutionary global best services to meet tourism demands. We are also interested in further studies in other contexts to continually validate the generalizability of the study findings and operationalize other measures of the criterion variable in the study.

\section{References}

Aggrey, K and Gerald C.J (2011), Talent Management in the Nigerian Subsidiaries of UK MVCs. West African Journal of Business Studies 7(4), 89-96

Ashtor, L \& Morton, B (2005). Talent Development, Management and Sustainability: A field Experience of HYPCO. Journal of Business Research, 18(13), $249-263$

Basil, C.A. (2007). Human Resource Management, Cici: Pelkan Press.

Bell, F.C (2007). Mining Professional Competencies: An In-Road to Talent Mapping. Journal of Innovation Management, 28(11), 431 - 442

Benzil, O.A. (2009). Talent Management: A Remodelling Approach for Virtual Firms. Innovation Practice, 15(3), 92104.

Bums, J.P and James, D (2012). Changing Talent Management Approach for Competitiveness, Journal of Development 37(5), 179 - 189

Candy, N.A. (2007). Talent and Intellectual Composite: What Mental Structuring Can do. Journal of Management Review, 14(4), 75-82.

Carlucci, K. Abel, P. Kalil, J \& Peters, O.A (2004).. Talent Building and Emergence of Core Resource Theory: The Debate and Propositions.. Journal of Research and Innovation, 23(16), 153 - 172 
Chong, C.W., Holden, T., Wilhelmij, P., Schmidt, R.A. (2000). Where does knowledge management add value? Journal of Intellectual Capital, 1(4), 366-380.

Ebeth, O.C. (2009). A Critical review of Human and Endowment Management, Management Journal, 8(2), 16-27.

Ejemuta, N (2011) Balancing Employee Work Skills for Organizational Goal Attainment. Journal of Business Development Studies, 3(6), 113-121

Ekong P.B \& Nelly L. (2008). Scheduling Talent Management Making it a Strategic Task, Journal of Management Studies, 2(1) 16-24.

Everest, A.A (2000). Mapping Competencies for SMEs Growth Human Resource Management Journal. 3(7), 18-23

Ezeani, S.I. (1998). Research Methods: A Realistic Approach. Ibadan, Elohim Publishers.

Gandoky, H. \& Bell, P.A. (2007). Issues in Talent and Knowledge Transfer in the Construction Industry. Journal of Knowledge Management, 36(3), 66-78.

Gulate, B. \& Rueyingho, L.O. (2008). The New talent Hunt: Managing the New technology, Benin: Dazel Pub Co.

Hansen, P. Libel A.J Granville, K.N (2010). Skills Retention and Incentivization: The Talent Quest, Journal of Human Resource Development 14 (2), 64-72

Hansen, V., Jimiriz, P.N., Maleke, O.N. (2011). The strategy for managing talents, Journal of Performance Management, 11(3), 223-247

Jaya, T. \& Harrison, M.I. (2007). Managing for Growth: Checking the Indices, Lagos: Belk Press.

Karien, P.D. \& Hilda, M.A. (2007). Measuring the Richness of Intellectual Capital in Firm Performance. Journal of Management Review.

Khanda, L.G. \& Sollywolf, B. (2000). Option for knowledge capital management: The paradox and the parts. Intellectual Management, 11(7), 548-560.

Klarkson, J. (2007). Talent, Skills and Competencies, Knowledge, London.

Koyen, C.M \& Neil, D (2009). Talent Management: Gaining A Competitive Edge Journal of Innovation 7(4), 32-41

Leonard, U. \& Zack, A.J. (2007). Reaching Out for the Invaluable Asset: The Talent Mining Approach, Journal of Management, 9(6), 41-48.

Marr, S.S \& Schuima, L (2001). Evolving a Theory of Talent Management, Illinois, Peabody Press.

McKay, L.C. (2008). Examining the business impact of talent management practice. Journal of Knowledge Management Practice, 7(8), 19-38.

Menalo, O.N. \& Akinson, E.E. (2010). Encouraging talent Build Up Programmes in the Public Sector. Journal of Management, 4(3), 41-60.

Molloway, M. \& Chanda, A.B. (2011). Building Trust and Empowerment in a Multi Racial Work Environment: The NACO Experience. Journal of Corporate Sustainability, 32(9), 593-612.

Morton, L. (2005). Talent Management Value Imperatives: Strategies for Execution, New York: The Conference Board.

Nabort, A., James, D.I., Ellen, K. (2007). Exploring the Database and Getting the Employee Fit. Management Review, 37(5), 262-268.

Nebrand, P. \& Cullan, K. (2009). Human Asset: The Case of Repository, London: Asap press.

Onuegbu A. \& Adare, B.C (2011), Leadership Talent Management and Confidence Building Among Junior Employee Journal of Business Studies 11(2), 73-79

Parks, A. \& Lynda, E. (2010). The Talented Enterprise: The Mediocrity Question, Journal of Corporate Sustainability. 11(5), 63-76.

Perini, B. (2007). Defining Key Talent Management Parameters for Organisational Performance. Innovation Management Journal, 10(1), 22-37

Peterson, O.G. (2013). Pushing for the Workforce, Antwerp: Gurril Press.

Philas, D. (2004). Implementing Corporate Talent Management Strategies in Medium Sized Firms, Journal of Corporate Sustainability, 16(2), 189-201. 
Pitterburg, N (2010). Employee Retention through Talent Mining and Acquisition. Journal of Coroporate Sustainability 6(10), 81-98.

Pittson, B \& James O.L (2007), A Dynamic Review of Talent Management. Journal of Business Management 6(6) $411-418$

Quincy, E.J. (2011). Corporate Strategy, San Jose: Lipsey Pub.

Saaty, C.L (2008). Geuderizing Talent Management: A Mapping Approach. Innovation Management Journal 16(9), 308- 317

Sugerion, D, \& Zardoskaya, G. (2001). New Perspectives on Intangible Assets and Organisational Performance. Journal of corporate Sustainability, 3(11), 108-121.

Tamare, T. (2006). The Role of Talent Management and Quality Improvement in Educational Competitiveness, Management and Technology Journal, 26(3), 8-19.

Teece, D.J. (2000). Strategies for managing knowledge asset: The role of firm structure and industrial context, Long Range Planning, 33, 35-45.

Teks, C.A. \& Sophil, J.A. (2010). Knowledge Management Goals: A Meta Analysis. Journal of Knowledge Management and Innovation, 7(12), 127-142. 